\title{
Außenpolitik der DDR: akribische Gesamtdarstellung, schwache Quellenkritik
}

\section{Wentker, Hermann: Außenpolitik in engen Grenzen. Die DDR im internationalen System 1949-1989, Oldenbourg Verlag, München 2007, 612 Seiten, € 49,80.}

Der langjährige sowjetische Botschafter in der DDR, Pjotr Abrassimow, beschrieb in einem am 11. August 1992 veröffentlichten Interview mit der früheren sowjetischen Parteizeitung „Iswestija“ die DDR als einen in der sowjetischen Retorte gezüchteten Homunkulus; der Moskauer Einfluss sei „präzedenzlos“ gewesen. Man habe die DDR in erster Linie als „unsere vorgeschobene Verteidigungslinie“ betrachtet. Auf außenpolitischem Feld waren die Abhängigkeiten von der sowjetischen Führungsmacht besonders groß, der Spielraum des SED-Staates entsprechend klein. Kann man angesichts einer solchen Lage überhaupt von eigenständiger Außenpolitik sprechen, und wenn ja, wo lagen deren Möglichkeiten und Grenzen? Hermann Wentker beleuchtet in seiner imposanten handbuchartigen Darstellung diese Frage von allen Seiten und über die gesamte Existenz der DDR. Seine Antworten können allerdings nicht immer überzeugen, nicht zuletzt weil er weitgehend auf eigene Archivstudien verzichtet und sich fast ausschließlich auf Sekundärliteratur stützt. Obwohl er bezüglich der Einbeziehung der Erinnerungen zahlreicher altkommunistischer Akteure ausdrücklich von der Notwendigkeit einer intensiven Quellenkritik spricht, lässt er genau diese zuweilen vermissen. So behauptet er zum Beispiel, Walter Ulbricht sei es gelungen, die Ablösung der sowjetischen Botschafter in Ost-Berlin, Georgi Puschkin (1958) und Michail Perwuchin (1962), zu erreichen; dabei beruft er sich allerdings ausschließlich auf die beiden sowjetischen „Desinformationsspezialisten“ Valentin Falin und Julj Kwizinskij.

Der Autor beschreibt die Rahmenbedingungen der Außenpolitik der DDR durchaus zutreffend. Diese hätte sich stets ,in den engen Grenzen, die durch die Abhängigkeit von der Sowjetunion, die deutsch-deutsche Konkurrenz und die eigene innere Entwicklung gezogen wurden (bewegt). Alle drei Faktoren zusammen bestimmten in einem wechselnden Mischungsverhältnis die Außenpolitik des ostdeutschen Staates“ (S. 563). Doch insbesondere bezüglich der Charakterisierung der Beziehungen zur sowjetischen Führungsmacht muss zumindest für einzelne historische Abschnitte Widerspruch zu den Positionen Wentkers angemeldet werden. Höchst fragwürdig ist etwa die von Hope M. Harrison übernommene Einschätzung der DDR als „super ally“ der Sowjetunion während der zweiten BerlinKrise $^{1}$, die den Einfluss Ulbrichts auf Nikita Chruschtschow stark überbewertet. Wentker behauptet sogar, der SED-Chef habe im Vorfeld des Mauerbaus dem zögerlichen Chruschtschow mit einseitigen Maßnahmen gegen die anhaltende Massenabwanderung "gedroht", eine einigermaßen abstruse Verkehrung der Machtverhältnisse. Möglicherweise entsprach die Entscheidung zum Mauerbau auch gar nicht den Präferenzen Ulbrichts, der wohl eher zu radikaleren Maßnahmen wie der ultimativen Forderung nach einer Kontrolle des Luftverkehrs zwischen Westdeutschland und West-Berlin durch DDR-Behörden neigte; die Sowjetunion wählte indes eine weniger riskante Strategie.

Ähnlich überzogen wirkt die Charakterisierung der DDR als „Friedensmacht“ während der „kleinen Eiszeit“ in den Ost-West-Beziehungen Anfang der achtziger Jahre; der SEDStaat hätte sich diesbezüglich profilieren und deutlich von der Sowjetunion absetzen kön-

1 Vgl. Hope M. Harrison, Driving the Soviets up the wall, Princeton 2003. 
nen. Die DDR betrieb aber auch damals keineswegs echte Friedenspolitik, vielmehr fügte sich der Kampf ausschließlich gegen NATO-Waffen, in den man auch die westdeutsche Friedensbewegung einzuspannen suchte, nahtlos in die unveränderten Hasskampagnen der DDR-Medien gegen den „imperialistischen Klassenfeind“ ein. Diese wurden bereits ab Ende der siebziger Jahre von einer verstärkten Militarisierung der gesamten DDR-Gesellschaft begleitet. Der „antifaschistische Schutzwall“ sollte laut Erich Honecker noch mindestens bis zum Jahre 2089 stehen, falls er nicht wie geplant von sowjetischen und ostdeutschen Waffenbrüdern gemeinsam überwunden worden wäre, um endlich den Berliner Westsektoren die Segnungen des Sozialismus zu bringen. Auch während der Polen-Krise 1980/82 agierte der SED-Generalsekretär keineswegs als sicherheitspolitische „Taube“, sondern befürwortete einen harten Kurs gegen den vermeintlichen Bruderstaat, der eine erneute militärische Intervention des Warschauer Paktes in einem seiner Mitgliedsländer keineswegs ausschloss. Statt von Friedenspolitik sollte also besser von (vorwiegend ökonomisch motivierten) Versuchen zur Minimierung der Folgen der durch den Ostblock ausgelösten neuen Aufrüstungsrunde gesprochen werden. Fragwürdig erscheint auch, ob Ost-Berlin bei seinem Einsatz für ein möglichst radikales Vorgehen gegen den Prager Frühling sowie gegen die Solidarnosc in Polen tatsächlich „weniger von einer aggressiven Ideologie als von Existenzangst angetrieben wurde“ (S. 556), wie Wentker meint.

Überhaupt unterschätzt der Autor den Einfluss der Ideologie auf die SED-Politik erheblich. Zwar konzediert er, dass diese „auch in der Außenpolitik die Wahrnehmungsmuster der DDR-Führung (prägte) und ... damit zum Teil eine realistische Beurteilung der politischen Kräfteverhältnisse (verhinderte)“ (ebenda), doch hätte die Ideologie für die DDRAußenpolitik „eher eine untergeordnete Rolle“ (ebenda) gespielt. Dies versucht Wentker unter anderem anhand der Verwendung des Begriffs „friedliche Koexistenz“ zu belegen, mit dessen Hilfe „sowohl konfrontative Auseinandersetzungen als auch Kompromisse mit dem ,Klassenfeind' als in Übereinstimmung mit den eigenen ideologischen Prinzipien erklärt werden“; damit sei der Begriff zu einer „manipulierbaren Generalklausel“ geworden, „die den Charakter außenpolitischer Beziehungen eher verschleierte als erklärte“ (ebenda). Doch genau darin lag ja die Hauptfunktion dieser „dialektischen“ Formel, ein kommunistischer Parteisoldat hätte den Einwand Wentkers überhaupt nicht verstanden. Obwohl die Ideologie zweifellos immer wieder zur Legitimation der SED-Politik herangezogen wurde, war sie keineswegs bloße Magd machtpolitischer Interessen. Stattdessen wurden „mit der Muttermilch aufgesogene" ideologische Prinzipien in aller Regel durchgehalten, bis sie so dramatisch zum Beispiel mit der außenpolitischen Realität kollidierten, dass nach pragmatischen Alternativen gesucht werden musste.

Ungeachtet aller prinzipiellen kritischen Anmerkungen ist dem Autor Respekt für seine akribische Gesamtdarstellung zu zollen. Sowohl die systematische Gliederung als auch die Gewichtung der einzelnen außenpolitischen Felder überzeugen. Somit kann der Band auch als Nachschlagewerk empfohlen werden, dem allerdings ein Schlagwortverzeichnis zu noch mehr Übersichtlichkeit verholfen hätte. 